\title{
FENESTRAE PARIETALES SYMMETRICAE
}

\author{
BY
}

\author{
TJ. HALBERTSMA, M.D.
}

(From the Paediatric Department, St. Elizabeth's Hospital, Haarlem, Holland)

Among the many new diseases which have been described during the present century, there are a remarkable number of diseașes of the osseous system. In some instances this is due to the necessity of x-ray examination and biochemical investigation for their diagnosis, but in others, such as osteopetrosis (AlbersSchönberg disease), osteochondrodystrophy (Morquio's disease), gargoylism (dysostosis multiplex), and hypertelorism, these aids were not essential, and it is perhaps surprising that the conditions escaped recognition until relatively late. The rarity of the conditions and the reluctance of writers of textbooks to list them as distinct diseases will also have militated against their general recognition.

In the case of fenestrae parietales symmetricae both causes have been operative. Probably this heredo-familial condition occurs more frequently than is generally supposed, but has received little attention. It is, however, entirely comparable to such a disease as cleidocranial dysostosis, which is widely known, not from personal experience but from its established place in textbooks.

The condition of fenestrae parietales symmetricae is characterized by the presence of symmetrical defects of the parietal bones, situated close together and occurring constantly in the same position. Their site is behind the crown, near the junction of the middle and posterior thirds of the sagittal suture. The defects are of oblong shape, the long axis lying at right angles to the sagittal suture. They vary from $\frac{1}{2}$ to 4 or $5 \mathrm{~cm}$. in length and 1 to $2 \mathrm{~cm}$. in width. The openings are covered with epidermis, and below this the dura can be felt to pulsate as in the anterior fontanelle of infants. Sometimes the openings are connected by a narrow aperture ; there is usually a tendency for them to become narrower. The defect on the right is often somewhat larger than that on the left.

It happens that in the normal skull a few openings are found in the same situation, which are, however, very small. These are the anatomical ' foramina parietalia' which serve to provide a connexion between the vessels of the galea and the superior longitudinal sinus. Their size is at most a few millimetres, and in many cases they are altogether absent.

In some anatomical museums, skulls with the large openings described above had been observed more than 150 years ago, and Lobstein described them in 1772. In 1919 Pamperl discovered thirty-six cases in the literature, of which five had been described in living persons and the remainder in museum specimens. In 1937 the total number had, according to Voigt, increased to forty-five mostly by observations made on living patients. Amongst these was 
one case observed in Holland and described in Dutch by Jonker (1933) under the title 'A congenital skull defect in an infant.' In this typical case the hereditary factor was demonstrable, since the mother of the affected child showed a similar condition though to a less degree. Jonker was also able to observe her patient from the age of eleven months to two years, so that she was able to follow the progress of the defect (see below).

At first these large openings were thought to be variations of the normal foramina, and the name 'foramina parietalia permagna' was considered suitable. Needless to say, earlier authors suggested various explanations for these large foramina. Increased numbers of blood vessels, or vessels of abnormal size, penetrating the skull were suggested as possible causes, or again local atrophy due to the rapidly growing brain. It is only comparatively recently that the conception of a developmental disturbance in the formation of the skull has held the day. It had been found that the ossification of the parietal bone begins from two centres, an upper and a lower, which centres subsequently grow together to form the parietal tuberosity. Ossification then proceeds radially to the periphery, but in the region of the posterior part of the sagittal suture this occurs less regularly. Shorter and longer osseous ' rays' alternate so that apertures may arise which are felt in the newborn as Gerdyan fontanelles. The large defects with which we are concerned were therefore explained on this basis, and the term ' foramina parietalia permagna' retained until recently.

In 1934, however, the subject was illuminated by a clear and well-illustrated article by Zarfl, in which he suggested the simple descriptive name 'fenestrae parietales symmetricae' for the condition ; this name has since been generally adopted. He pointed out that the term 'foramina parietalia permagna' was deceptive, since it implied that the openings were identical with the normal anatomical parietal foramina. Zarfl was able to follow accurately for several years the exact course of events in the case of a premature baby. At first there appeared to be a large median bony defect, $5 \frac{1}{2}$ to $4 \mathrm{~cm}$. in size, a so-called accessory fontanelle, situated exactly between the two normal fontanelles. By the growth of a median partition in the course of two years this picture changed, and the two typical openings arose. Zarfl was also able to discover the skull of a newborn child in a Viennese anatomical collection which showed a similar accessory fontanelle as a single large orifice. If this child had survived, it would probably also have shown symmetrical fenestrae. When Zarfl, however, claims to have been the first to observe this development of the fenestrae he is in error, since Jonker had preceded him by a year. In Jonker's case, the two openings had already appeared at the age of eleven months, but on the medial side they still remained in direct connexion with the remainder of a lozenge-shaped accessory fontanelle. When the patient was two years old the accessory fontanelle had closed, and typical fenestrae had formed.

\section{Case reports}

The present study is concerned with the occurrence of fenestrae in a family of seventeen persons. This family, which comes from a village near Haarlem, consists of a grandfather and grandmother, who are not related ; six children ; 
and, up to the present time, nine grandchildren. One younger son is not yet married. In five persons the malformation was demonstrated (see fig. 1 in which pedigree the affected persons are shown in black).

No other congenital abnormalities such as have been described by other authors, viz. tower-head or spina bifida, have occurred in any member of this family. They were not specifically $x$-rayed for spina bifida occulta, but enuresis did not occur. The affected members of the family were of no special type, and there was nothing to distinguish them in other respects from their

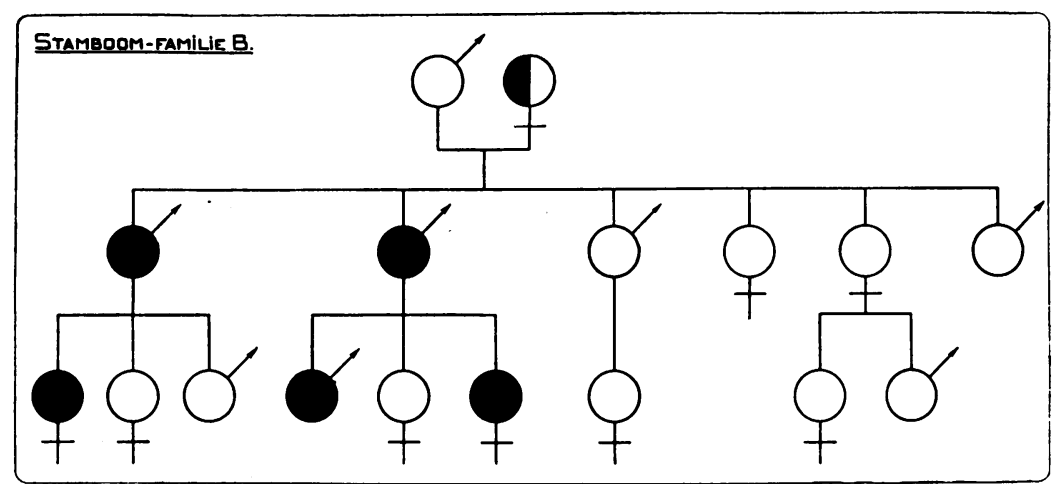

FIG. 1.-Pedigree of family B. showing fenestrae parieteles symmetricae ; dark symbols, affected members; the case of grandmother (black-white) is dubious.

normal brothers and sisters, with the possible exception of headache from which they suffered occasionally.

THE GRANDPARENTS, who were born in 1866 and 1876 respectively, did not show the abnormality at first sight. The grandfather is dolichocephalous and has a smooth, well-closed skull. There was no occasion to have a skiagraph made. The grandmother, however, who comes from Zeeland and is brachycephalous, shows on careful palpation a slight bilateral excavation of the parietal bones in the typical situation of fenestrae parietales symmetricae, the dimensions of the depression being 2 or $3 \mathrm{~cm}$. by 4 or $5 \mathrm{~cm}$. These areas, though depressed below the surface, are not compressible and do not pulsate. No fenestrae were visible in the skiagraph of the skull. The latter appeared very solid and slightly acromegalic ; it is not unlikely that previously she had shown skull defects and that the abnormality had come from her side of the family. She had not, however, heard of any abnormalities of the skull amongst her relatives in Zeeland. She complains of pressure on the occiput and rather frequent headaches. In the pedigree she has been indicated as a doubtful case.

Of their six children, the first two sons both show the defect ; two younger sons and two daughters are exempt from it. Amongst the grandchildren, the defect has so far only occurred in the children of the two eldest sons.

HARK B., born 1895, the eldest son, is a sturdy man, in whose skull the two small pulsating openings can be distinctly felt. He was passed for military service, but probably at that time the affection (which he had not mentioned) was overlooked. He has few complaints, and only of recent years on excessive exertion has he been aware of a 'heavy feeling' in his head in the region of the fenestrae, which he imputes to the latter. On x-ray examination, two fine fenestrae are visible, which, however, are smaller than those of his brother. The edges are smooth (see fig. 2).

He has three children, of which only the eldest, a girl, Gerda, born in 1922, 


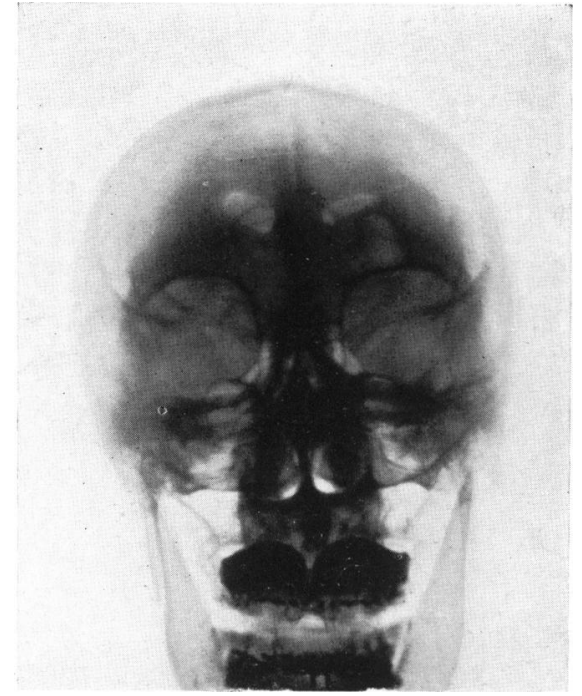

Fig. 2.-Hark B., father to Gerda. Age 42 years.

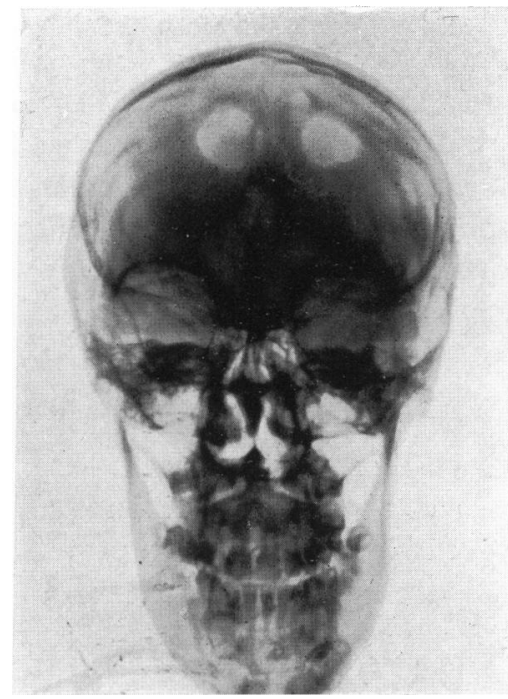

FIG. 3.-Gerda B., daughter to Hark. Age 17 years.

shows the defect (fig. 3). In her case the openings are almost round. She has no symptoms related to them.

DAAN B., born 1889, the second son of the grandparents, is likewise a sturdy man. He was exempted from military service after the family doctor had drawn the attention of the examining physicians to the affection. The bone-defects are with him relatively large, but they cause him little trouble, though they pulsate strongly; pressure on the spots, for example during a hair-cut, is disagreeable to him, and he also has sometimes a spontaneous and peculiar pain in his head, which he distinguishes from ordinary headache, and which he localizes in the defects; this pain appears when he is tired. His

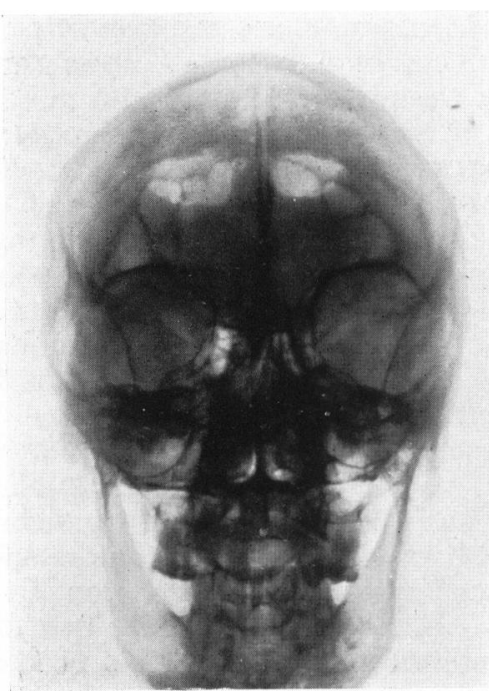

FIG. 4.-Daan B., father to Arie and Catherina. Age 41 years.

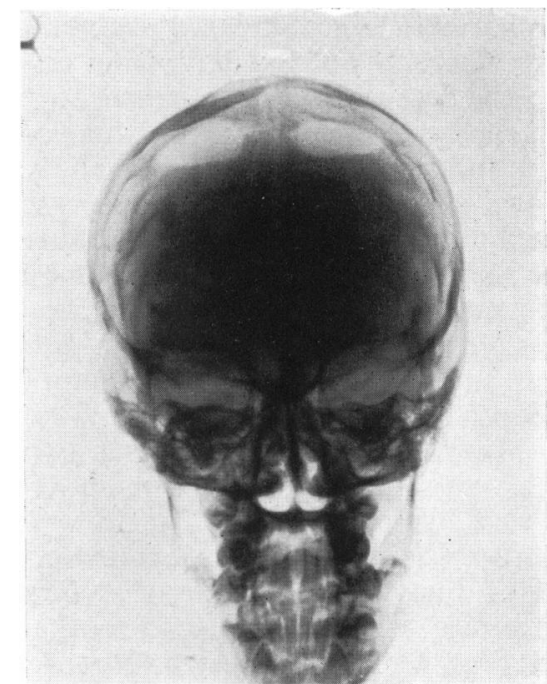

Fig. 5.-Arie B., son to Daan. Age 7 years. 
skiagraph is typical ; the edges of the openings are crenated, and also the opening on the right side is the larger (fig. 4).

About the three children of this son I can be somewhat more circumstantial, because it was possible to submit them to a regular medical examination.

ARIE B., a boy born in 1932, was first seen in 1935 with general symptoms.

He was then three years old, suffered from chronic infections, and had enlarged tonsils. His skeleton was strikingly slender. The skull already showed the complete fenestrae with a closed anterior fontanelle. Over the two skull defects a distinct pulsation was felt, which has become progressively less obvious in the course of time, so that now (1939) it is hardly recognizable. On x-ray examination (October 1939) the typical defects are nevertheless to be seen as large holes (fig. 5). The opening on the right is larger than that on the left.

JANNA B., the second child of this father, born in 1934, appeared to be free from the affection, and no defects were visible on $\mathrm{X}$-ray examination.

CATHERINA B., the youngest child, born in 1938, was first examined at the age of four weeks. There was at that

Fig. 6.-Catherina B., daughter to Daan. Age $1 \frac{3}{4}$ years. time a large fontanelle with posteriorly a widely patent sagittal suture. This latter merged posteriorly with two lateral defects, lying laterally and communicating with each other, thus forming a $\mathrm{T}$ (fig. 7). As the child appeared exudative, I saw it repeatedly, and was on each occasion able to mark out the shape and size of the defects. At the age of about a year, a separation arose between the vertical and transverse portions of the $T$. The vertical portion of the $T$ had gradually begun to assume a dumbbell form (fig. $7 \mathrm{~b}$ ), and at the age of sixteen months, the anterior expansion of the space represented the anterior fontanelle, and the posterior expansion an accessory fontanelle. Unlike the cases seen by Zarfl and Jonker, there was here no connexion between the accessory fontanelle and the oblong opening from which the fenestrae subsequently arise.

When the child was one and three-quarter years of age, the anterior portion of the skull showed little change, but posteriorly a small bony partition could

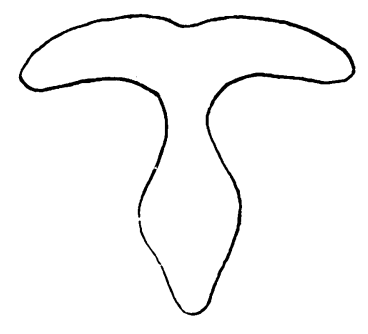

FIG. 7a.

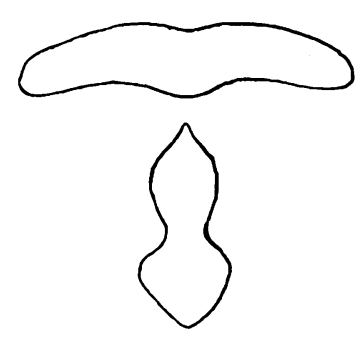

Fig. $7 b$.

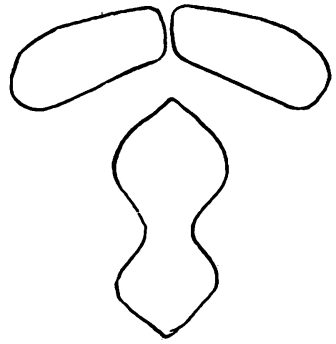

FIG. 7c.

7a. The T-shaped skull defect at the age of 4 weeks of Catherina B.

$7 \mathrm{~b}$. The transverse defect is loose from the dumbbell shaped front. The fenestrae still connected. Age 16 months.

7c. Formation of the two fenestrae by intergrowth of a narrow partition. Age $1 \frac{3}{4}$ years. 
be felt, in the mid-line, dividing the oblong opening into a right and left half (fig. 7c). The bony division was $\frac{1}{2} \mathrm{~cm}$. broad. The skiagraphs were hard to interpret, but in fig. 6 the large defect is well seen, though nothing is yet visible in this picture of the narrow bony division mentioned above. Thus it appears that the fenestrae arose from the division of a congenital defect of the skull of much greater size. This was not, as in the cases described by Zarfl and by Jonker, a large accessory fontanelle but a T-shaped defect.

\section{Discussion}

Both an hereditary and familial incidence of the condition had been observed by Neurath in 1922, a mother and two of her three children being affected in one instance and a mother and her only child in a second. Before then only one hereditary case appears to have been described, that of Symner (a father and son). Since 1930 other examples of the condition occurring in parents and children have been recorded (Lelong and Bosquet, 1932 ; Häszler, 1936 ; Wissler, 1938). In most of these later publications, Zarfl's description 'fenestrae parietales symmetricae' has been employed.

The best observation, however, is that of Voigt (1937), who was able to study a family of fifteen persons in which the abnormality occurred in three generations. Marquézy (1939) also recently described 'lacunes congenitales de la voûte cranienne' in an infant, the mother, and the maternal grandfather. The present description of this Dutch family is closely comparable to that of Voigt. What distinguishes this family from most foreign observations is the absence of other congenital abnormalities.

\section{Summary}

A family of seventeen persons is described, five of whom showed fenestrae parietales symmetricae, whilst one individual (the grandmother) showed depressions in the same situation in the parietal bones. Other congenital abnormalities were not present in the family. The older members of the family complained of vague headaches.

In the case of one of the grandchildren, the condition could be observed from the age of one month, when the openings were already present as the transverse portion of a.T-shaped cranial defect. The communicating fenestrae were not separated by a median bony division until the age of one and three-quarter years.

The term fenestrae parietales symmetricae (Zarfl) is considered preferable to the older description, foramina parietalia permagna.

The condition is probably not uncommon.

\section{REFERENCES}

Häszler, E. (1936). Mschr. Kinderheilk., 64, 337.

Jonker, A. (1933). Maandschr. Kindergeneesk., 3, 80.

Lelong, M., and Bosquet (1932). Bull. Soc. Pédiat. Paris, 30, 161.

Lobstein, quoted by Voigt (1937).

Marquezy, R. A. (1939). Nourrison, 27, 294.

Neurath, R. (1922). Z. Kinderheilk., 32, 121.

Pamperl, R. (1919). Dtsch. Z. Chir., 148, 91.

Symner, quoted by Voigt (1937).

Voigt, R. (1937). Mschr. Kinderheilk., 70, 224.

Wissler, H. (1938). Arch. Kinderheilk., 115, 217.

Zarfl, M. (1934). Z. Kinderheilk., 57, 54. 